The 102 women were a very assorted group in shape, size, age, and occupation, as they were chosen only by their length of sentence. As a toxic reaction was found only in $3 \%$ and was of a mild nature it can be assumed that it is safe and probably advantageous to give metronidazole in twice-daily doses.

I thank Dr. Martin Hynes, consultant pathologist to the Royal Northern Hospital, and his laboratory staff for culturing and reading our specimens, and Dr. P. M. Button for her help in taking the tests. I am indebted to the Prison Commissioners for giving me permission to publish this paper. I thank May \& Baker Ltd. for generous supplies of "flagyl."

BiBLIOGRAPHY

Burch, T. A., Rees, C. W., and Reardon, L. V. (1959). Amer. J. trop. Med. Hyg., 8, 312 .

Cosar, C., and Julou, L. (1959). Ann. Inst. Pasteur, 96, 238.
Durel, P., Couture, J., Collart, P., and Girot, C. (1960). Brit. J. vener. Dis., 36, 154

Roiron, V., Siboulet, A., and Borel, L. J. (1959). C.R. Soc. franç. Gynéc., 29, 36.

- (1960). Brit. J. vener. Dis., 36, 21

Feinberg, J. G., and Whittington, M. J. (1957). J. clin. Path. 10, 327 .

Fortier, L. (1960). Gynaecologia (Basel), 149, Suppl. p. 158.

Mascall, N. (1954). Brit. J. vener. Dis., 30, 156.

Moffett, M., and McGill, M. I. (1960). Brit. med. J., 2, 910.

Nicol, C. S., Barrow, J., and Redmond, A. (1960). Brit. J. vener. Dis., 36, 152.

Perl, G., Guttmacher, A. F., and Raggazoni, H. (1956). Obstet. and Gynec., 7, 128.

Rees, E. (1960). Brit. med. J., 2, 906.

Rodin, P., King, A. J., Nicol, C. S., and Barrow, J. (1960). Brit. J. vener. Dis., 36, 147.

Scott-Gray, M. (1961). J. Obstet. Gynaec. Brit. Cwlth, 68, 723. - and Murrell, M. (1961). Practitioner, 186, 218.

Trussell, R. E. (1947). Trichomonas Vaginalis and Trichomoniasis. Blackwell, Oxford.

Watt, L., and Jennison, R. F. (1960). Brit. med. J., 2. 902.

Will (1962). Ibid., 1. 276.

Willcox, R. R. (1960). Brit. J. vener. Dis., 36, 175

\title{
SUPERIOR MESENTERIC ARTERY OCCLUSION TREATED BY ILEO-COLIC AORTIC ANASTOMOSIS
}

\author{
I. RANGER, M.B., B.S., F.R.C.S. \\ Surgical Assistant, Middlesex Hospital, \\ London
}

Complete occlusion of the superior mesenteric artery usually results in necrosis of the small gut. If, however, the obstruction is not complete the blood supply, either direct or by anastomotic channels, may be sufficient to maintain the viability of the bowel, but not be adequate during periods of increased demand, as after meals. This inadequacy may result in postprandial pain sometimes associated with malabsorption (Shaw and Maynard, 1958). Dunphy (1936) used the term "abdominal angina" to describe the syndrome. $\mathrm{He}$ was the first to point out that such symptoms might be a premonitory signal to the development of massive infarction, commonly preceding it by three months and in some patients by as long as two years. Abdominal angina is difficult to diagnose and the proportion of patients in whom the diagnosis is established before the development of intestinal infarction is small. In the last few years various types of operation have been performed, with success in a few cases (Shaw and Maynard, 1958 ; Morris et al., 1962). Recently we have treated a patient successfully by direct anastomosis of the ileo-colic artery to the aorta. This particular type of by-pass operation does not seem to have been used before.

\section{Case History}

A 54-year-old labourer was admitted to hospital in November, 1961, for investigation of the symptom of diffuse abdominal pain. The pain was of two months' duration, worse immediately after meals, eased slightly by lying down, but was never completely relieved. Vomiting of food occasionally occurred at the height of the pain and recently there had been intermittent diarrhoea with up to eight motions a day. Neither vomiting nor defaecation relieved the pain. There was a 10-year history of angina pectoris and a three-year history of intermittent claudication.

Examination revealed a thin man looking older than his years. Blood-pressure $170 / 80$; in the lower limbs no pulse was palpable distal to the femoral arteries. There was a systolic bruit over the central abdomen and both groins, but otherwise the abdominal examination was negative.

Investigations.-Faecal fat excretion: $11 \mathrm{~g}$./day (threeday mean on a normal ward diet). Electrocardiogram: old anterior myocardial infarction with recent ischaemic changes. Glucose tolerance test: blood-sugar levels, 93,
BY

\author{
M. P. SPENCE, M.B., B.Chir., M.R.C.P. \\ Senior Medical Registrar, Middlesex Hospital, \\ London
}

$144,166,173$, and $160 \mathrm{mg} . / 100 \mathrm{ml}$. fasting and at halfhourly intervals after ingestion of $50 \mathrm{~g}$. of glucose. Other investigations, including barium studies of the stomach and small and large bowels, showed nothing abnormal.

In hospital severe pain was present after every meal and was not relieved by atropine, trinitrin tablets, or propantheline. The patient refused to eat more than a very small meal because of the pain. That the pain probably originated in the small intestine was demonstrated when an attempt was made to study motility by a method involving the passage of a Cantor tube. The tube was anchored by strapping to the patient's cheek. When it became taut he experienced an intense exacerbation of his pain, relieved by releasing the strapping.

Aortography showed that the superior mesenteric artery was very narrow and irregular, in its proximal $3 \mathrm{~cm}$. being only 1-2 $\mathrm{mm}$. in diameter. The few vessels supplying the small bowel were small in calibre and showed reduced linear flow rate. The inferior mesenteric artery was patent and had an unusually large left colic branch. The branches of the coeliac axis were substantially normal. Both renal arteries were narrow at their origins.

The patient's symptoms increased in severity so that in addition to the postprandial symptoms he complained of severe and constant abdominal pain. Because of the severity of the pain laparotomy was performed.

Operation.-Laparotomy on January 21, 1962, revealed that the small bowel was abnormally pale. No area of infarction was seen. No pulsation was seen or felt in the vessels of the small gut, although there was very little fat in the mesentery. The middle colic and right colic arteries also showed no sign of pulsation. A hard calcified area 3-4 cm. long was palpable in the superior mesenteric artery extending from its origin to a point just distal to the middle colic artery. The inferior mesenteric artery showed wellmarked pulsation which extended to the sigmoid branches. The ileo-colic artery was $4 \mathrm{~mm}$. in diameter and free of palpable atheroma. Arteriotomy revealed only poor retrograde flow. Direct side-to-side anastomosis was performed between the ileo-colic artery and the aorta over a length of $1.5 \mathrm{~cm}$. at a site in the aorta distal to the inferior mesenteric artery (see Diagram). On release of the clamps good pulsatile flow was seen in the ileo-colic artery, and before closure of the abdomen pulsation was visible throughout the mesentery of the gut. The bowel returned to the normal pink colour. 


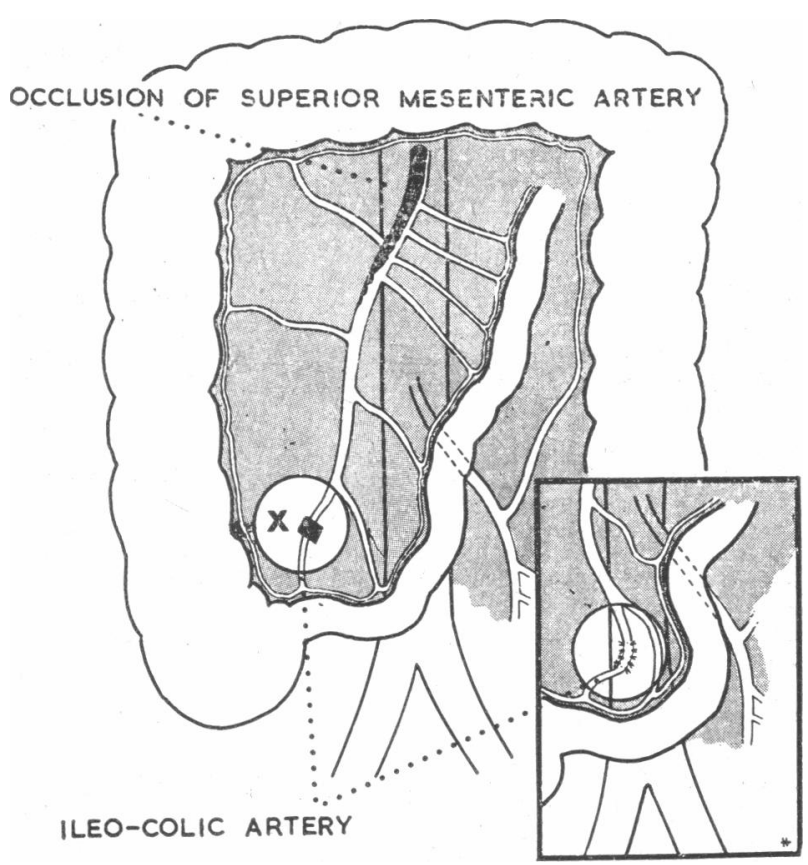

Diagram showing extent of occlusion of the superior mesenteric artery and the site in the ileo-colic artery chosen for anastomosis

to the aorta. The inset depicts the completed anastomosis.

On regaining consciousness the patient spontaneously said that he had completely lost the constant abdominal pain. Subsequently he was able to eat larger meals than for a year and was entirely free from postprandial pain. His post-operative recovery was uneventful. At the time of writing he remained free of abdominal pain.

Comment.-It is of interest that success was achieved in this case using the ileo-colic artery, a blood-vessel much smaller than vessels found to be of practical value in peripheral vascular surgery. The run-off from the distal vessels rather than the diameter of the vessels probably, however, determines the likelihood of success, and the splanchnic vessels obviously constitute an enormous run-off area.

\section{Summary}

A typical case of abdominal angina due to superior mesenteric artery occlusion is described, in which complete relief of the patient's symptoms resulted from direct anastomosis of the ileo-colic artery to the aorta.

We thank Mr. D. H. Patey and Dr. H. L. Marriott, under whose care the patient was admitted, for permission to publish this case, and Dr. J. N. Pattinson, who carried out the aortography and reported on the aortograms.

\section{REFERENCES}

Dunphy, J. E. (1936). Amer. J. med. Sci., 192, 109.

Morris, G. C., Crawford, E. S., Cooley, D. A., and DeBakey, M. E. (1962). Arch. Surg., 84, 95.

Shaw, R. S., and Maynard, E. P. (1958). New Engl. J. Med., 258, 874

A new Government health centre, to be known as the Robert Black Health Centre after the Colony's Governor, Sir Robert Black, is to be built at San Po Kong, a rapidly developing industrial and residential area near Hong Kong's international airport at Kai Tak. The construction cost of about $£ 37,500$ will be met jointly by Dr. Tang Shiu-kin and the Government. The ground floor of the three-story building will be used as the out-patient department. There will be four consulting-rooms and a dispensary, as well as rooms for minor operations and treatment. A 24-bed maternity ward and a maternal and child health centre will occupy the first floor. The second floor will be used as staff quarters.

\section{Medical Memoranda}

\section{Rupture of the Spleen in Infectious Mononucleosis}

Rupture of the spleen in infectious mononucleosis (glandular fever) is a rare complication of a usually benign disease. It has only comparatively recently been recognized, for Tidy (1934) and Bernstein (1940) do not mention it in their comprehensive reviews. Garfield and Gentry (1959) report 31 cases in the literature in addition to the one they add, and at least three more cases in the English language literature can be added to this (Wagman, 1957 ; Davidson, 1958 ; Ridgley, 1960). When it occurs there is an unduly high mortality rate. Smith (1956) records a mortality of $33 \%$ (7 out of 21 cases). Among the causes of spontaneous rupture of the spleen it stands high: reviewing the 44 cases of spontaneous rupture of the spleen in United States Army records, Smith and Custer (1946) found that $50 \%$ of the 44 cases were malarial, and 7, the next largest group, were due to infectious mononucleosis.

Rupture of the spleen usually presents as abdominal pain complicating a known case of mononucleosis or of persistent sore throat (Davidson, 1958), for it takes about two weeks for the pathological changes in the spleen which cause it to rupture to come about. These changes have been described (Erwin et al., 1959) as an infiltration of the capsule with lymphocytes and monocytes, increase in bulk of the splenic pulp, and blurring of the normal architectural pattern. However, as the following case shows, the presentation may be as an acute abdominal emergency.

\section{CASE REPORT}

A 20-year-old white male student was admitted to the emergency room of Cornell University Infirmary at 9 a.m. on February 18, 1961, complaining of severe upper abdominal pain and pain in both shoulders. He said that about an hour previously he had had a normal bowel movement and on returning to his bedroom lay prone on his bed with his buttocks in the air and attempted to pass flatus per rectum. He then felt a sudden pain throughout his abdomen and " nearly collapsed." A few minutes later he felt sharp pain in his right shoulder which went down the outside of the arm towards the elbow, and also a slight pain in the left shoulder.

Before the onset of the pain he had been well except for a slight cough and congestion of the nose. He had had no indigestion and no abnormality of bowel function or of urination. Later examination of his record showed that he had been to the student out-patient clinic five days previously because of a cold and that pharynx and chest were then normal on examination, but he had a thick nasal discharge. He had been given oral penicillin $G$ tablets (250,000 units q.i.d. for four days). He had had no serious illness (other than childhood exanthemata) but had attended the out-patient clinic three times during the current academic year because of upper respiratory infections. On examination he was co-operative but obviously in pain. Temperature was $97^{\circ} \mathrm{F}$. $\left(36.1^{\circ} \mathrm{C}\right.$.), pulse regular $100 / \mathrm{min}$., and blood-pressure $105 / 60 \mathrm{~mm}$. Hg. The pharynx was diffusely reddened and there were soft hypertrophied lymph nodes in all cervical groups and in the right axilla. There was generalized tenderness on palpation of the abdomen although there did not appear to be muscle spasm. There was dullness to percussion across the whole of the upper 